\title{
Influence of Supervisory Style on Supervision Outcomes among Undergraduate Trainee Counsellors
}

\author{
GHAZALI, N.M ${ }^{*}{ }^{1}$, BEDDU N. ${ }^{2}$, WAN JAAFAR W.M. ${ }^{3}$, ANUAR A. ${ }^{4}$, ADEN, E. ${ }^{5}$, YAHYA.F. ${ }^{6}$ \\ $1,2,4,5, \& 6$ Faculty of Cognitive Sciences and Human Development, UNIVERSITI MALAYSIA SARAWAK, MALAYSIA \\ ${ }^{3}$ Faculty of Educational Studies, UNIVERSITI PUTRA MALAYSIA, MALAYSIA \\ *E-mail: gnmazlina@unimas.my
}

\begin{abstract}
The research aimed to identify the influence of supervisory styles on supervision outcome among undergraduate trainee counsellors. This research was quantitative with correlational research design in order to identify the influence and relationship between independent and dependent variables among trainee counsellors. 100 respondents from two (2) public universities in Malaysia were recruited. Stratified random sampling technique was utilized to select the respondent and proportional stratification was used to determine the sample size of each stratum. Supervisory Styles Inventory (SSI) and Supervisory Satisfaction Questionnaire (SSQ) was the instrument used in this study. The System Approach to Supervision (SAS) Model become underlying theory in this research. The results of the study were analysed by using Pearson's product-moment Coefficients and Multiple Regression. Based on the findings, the supervisory styles showed that there was significant relationship with supervision outcome $(r=0.49, p<0.05)$. Three of supervisory styles which were attractive $(r=0.48, p<0.05)$, interpersonally sensitive $(r=0.48, p<0.05)$ and task-oriented $(r=0.42, p<0.05)$. The supervisory styles also showed there was significant influence with supervision outcome. Among the three supervisory styles, attractive and interpersonally sensitive was the most influence on supervision outcome $\left(R^{2}=0.23\right.$, Adjusted $\left.R^{2}=0.22, F(1,98)=29.05, p<0.05\right)$. The findings of this study perhaps could expand knowledge and understanding on the individual differences to supervision field. Supervisors could examine and reflect upon their styles based on theoretical framework provided and can restructure the styles. Lastly, it also can improve the quality and effectiveness of supervision for both supervisor and supervisee.
\end{abstract}

Keywords: Supervisory Style, Supervision Outcomes, Trainee Counsellors, Satisfaction

Classification JEL: C1, L2 


\section{Introduction}

The style of supervision among supervisors giving impact to professional development of supervisees, and it will become guidance for supervisees to manage their career in life (Herbert \& Ward, 1990; Ladany, Walker, \& Melincoff, 2001). According to Patton and Kivlighan (1997), the supervisory style and personality are become dominant effect towards professional development and counselling relationship of supervisees. Supervisor in supervision process play a role as role model for supervisee who are being supervised as well as the client are receiving the effectives counselling session (Bernard \& Goodyear, 2009; Hensley, Smith, \& Thompson, 2003; Morgan \& Sprenkle, 2007; Nelson \& Holloway, 1990). In addition, according to Dye and Borders (1990) the supervisor has capable in term of knowledge and skills related to counselling. The supervisory style that become significant in supervision process is supportive style (Nur Hafizah Mohd Ali, Siti Aishah Hassan \& Othman Jailani, 2014). In addition, the supervisory style had significant significant positive correlations with supervisee disclosure in supervision (rattractive $=.36, p<.01$; rinterpersonally sensitive $=.42, \mathrm{p}<.01 ;$ rtask-oriented $=.32, \mathrm{p}<.01$ ).

In counselling supervision, supervisor work directly with trainee counsellor either individual or group. The interaction between supervisors and supervisees (trainee counsellors) shows pronounced effect on the supervision process and outcome. Supervisory style is defined as the personal manner of supervisors' when interact with and supervisees' (Friedlander \& Ward, 1984). Previous research mentioned the attractive attributes of supervisors such as warmth, empathy, flexible and supportive to supervisees (trainee counsellors) while supervision process. In addition, supervisor who are sensitive with supervisees' condition become significant style of supervisory as well as good engagement with supervisees. Third style which is task-oriented also become dominant style in supervisory process. Understanding the supervisees' style enable to assist them to professionally develop and beneficial to supervisees along their career life (Herbert \& Ward,1990); Ladany et al.,2001). However, in Malaysia there is no empirical studies posited that supervisors use a variety of styles and approaches while working directly with their supervisees (Bernard, 1979, 1997; Carroll, 1996; Friedlander \& Ward, 1984; Hess, 1980; Holloway, 1995; Stoltenberg \& McNeill, 1997; Williams, 1994) which ultimately affects overall supervisees' experiences both during and after supervision but there is no empirical study has addresses the relationship between supervisory styles on supervisions outcome (satisfaction).

Different styles showing different traits and characteristics and Bernard (1997) has indicated importance of flexibility in supervisor as supporting the development of supervisees. Hopefully, this research could bring some understanding and ideas to the counsellors, educators and supervisors on the influence of supervisory styles to supervision satisfaction outcome.

Research related to supervision has been newly develop in the counselling field in Malaysia. Supervisory style is relevant to supervision process and some variable outcomes and the study found that supervisor styles have relationship with frequency of supervisor's self-disclosure during the supervision (Ladany \& Lehrman-Waterman,1999) but the study on supervisory style in Malaysia is lack of research (Fernando \&HulseKillacky, 2005; Shuss , 2012 \&Terranova Nirenberg, 2013).

Findings from several literatures from Bernard (1979; 1997); Carroll (1996); Friedlander \& Ward (1984); Hess (1980); Holloway (1995); Stoltenberg \& McNeill (1997); Williams (1994), they stated the supervisors are implemented varies style and approaches of supervision. Apart from that, the supervisor aims supervisees (trainee counsellors) to have experience while supervision process. However, those researchers were not highlighted on the relationship between supervisory styles on supervisions outcome (satisfaction). In current research, the supervisory relationship showed an essential factor for obtaining the successful outcomes and empowering the development and self confidence among trainee counsellors (Corey, Haynes, Moulton, \& Moratori, 2010; Nelson\& Friedlander, 2001). Thus, findings this research could contribute some useful information and data on predicting the dominant influence of supervisory style on supervision outcome in Malaysia to deliver the gap. 
The past research studied many took the target population from doctoral level students' population and master levels counselling student's population (Terranova-Nirenberg, 2013; Berger, 2012; Fernando \& Hulse Killacky, 2005). There is no continuous research in supervisory style, and it is considering as undergraduate population. Thus, this study takes the target population from undergraduate counselling students in Malaysia to deliver the gap according to the influence of supervisory style on supervision outcome. Another methodology gap was present by TerranovaNirenberg (2013) which focus only for the female respondent. This may cause the generalizability of the results which may affects the external validity in this research study. Thus, in this research, heterogeneous sample involving both gender of female and male will be taken as the respondent to deliver the gap.

\subsection{Research Objectives:}

a. to investigate the relationship between supervisory style (attractive, interpersonally sensitive and task-oriented) on the supervision outcome (trainee counsellors' satisfaction).

b. to investigate the influence of supervisory style (attractive, interpersonally sensitive and taskoriented) on the supervision outcome (trainee counsellors' satisfaction).

\subsection{Research Hypotheses:}

$\mathrm{H}_{01}$ : There is no significant relationship between supervisory style and the supervision outcome (trainee counsellors' satisfaction)

$\mathrm{H}_{02}$ :There is no significant relationship between supervisory style (attractive) and the supervision outcome (trainee counsellors' satisfaction).

$\mathrm{H}_{03:}$ There is no significant relationship between supervisory style (interpersonally sensitive) and the supervision outcome (trainee counsellors' satisfaction).

$\mathrm{H}_{04}$ : There is no significant relationship between supervisory style (task-oriented) and the supervision outcome trainee counsellors' (trainee counsellors' satisfaction).

$\mathrm{H}_{05}$ : There is no significant influence of supervisory style between supervisory style (attractive, interpersonally sensitive and task-oriented) and the supervision outcome (trainee counsellors' satisfaction).

$\mathrm{H}_{06}$ : There is no significant influence between supervisory style (attractive, interpersonally sensitive and task-oriented) and the supervision outcome (trainee counsellors' satisfaction).

\section{Literature Review}

\subsection{Supervisory Style}

While reviewing on the empirical literature of developmental influence on supervisory styles, several research studies state that supervisory style are relevant to supervision process and some variables outcome. Research of Ladany and Lehrman-Waterman (1999) found that his supervisory styles were associated with the frequency of supervisor's self- disclosure during the supervision. Result from the research, showed an attractive supervisor is more likely to reveal counselling experience or issue compare to another two styles.

Another point to mention is that the supervisory styles could be predicted by theoretical orientation of supervisors. In the study, Friedlander and Ward (1984), supervisors who apply psychodynamic approach were highly interpersonally sensitive while for those who adopt cognitive behavioural approach were highly task-oriented. Based on the literature review, researchers conclude that a flexible engagement to various supervisory styles may enhance the supervisory relationship. However, a supervisor should always concern on the needs and expectations of the trainee's stages of development in ensuring the appropriateness of supervision style.

According to Nor Mazlina Ghazali, Josephine Lo Jing Wen, Azzahrah Anuar and Edris Eden (2018) that use System Approach to Supervision (SAS) model to know the reliability analysis of SSI that involved 30 students from the Bachelor of Counselling program at UNIMAS who are undergo 
practicum training. All subscales showed high internal consistency (reliability) at $\alpha=.87$ to $\alpha=.92$. Internal consistency for the three (3) subscales is (i) attractive at $\alpha=.92$; (ii) interpersonally sensitive $\alpha=.87$; and (iii) task-oriented $\alpha=.92$. Supervisory style of supervisors towards supervisees was reliable to measure by SSI. This showed that this instrument (SSI) is appropriate to be used in gathering information and data from particular respondents.

In addition, according to Friedlander and Ward's (1984) analysed the reliability as established, where the alpha Cronbach at .76 to .93 . Then, the correlation inter-items is at.70 to .88 for the attractive scale, followed by interpersonally sensitive scale at .51 to .82 and the task-oriented at .38 to .76. Furthermore, the Friedlander and Ward's (1984) was conducted the test-retest is two-week reliability in order to assess the master level supervisees at .92, individual scale at .92; attractive at .94 ; interpersonally sensitive at.91 and task-oriented at .78. Based on the analysis, it shows that the scale of SSI had strongly related and significant to the supervision.

According to Baker (1991), the attractive style perception in SSI was connected with WAIS and the subscale of the interpersonally sensitive style of the SSI was interrelated with component in WAIS. According to Ladany et al. (2001), the supervisors who are dominant in the attractive style have engagement with an emotional bond, goals and tasks subscales in WAIS. Then, the perception among supervisors on style of supervision was correlated to the working relationship between supervisor and supervisees (trainee counsellors). The individual that performed and good at interpersonally sensitive and task-oriented had better in completing aims of supervision. Other than that, the supervisors who implemented the attractive style was also perceived that self-disclosure with supervisees during supervision process (Ladany et al., 2001).

Conflict may happen when supervisors usually adopt an evaluative, task-oriented styles when work with inexperienced trainees and interpersonally styles when work with more experienced counsellors (Friedlander \& Ward, 1984). In addition, conflict also may happen when supervisors respond differently than a trainee expects or has experienced in the past. Thus, it would be better if supervisors consider the trainees' developmental level when choosing styles because trainees have different professional needs and expectation for their supervisors at different level and the supervisory styles may change corresponding to the need of trainees based on the literature above. For instance, although integrate supervision styles is encouraged, researchers have suggested to make task-oriented style to be dominant supervisory styles during with inexperienced counsellors (Ladany et al., 2001; Fernando \& Hulse-Killacky, 2005; Stoltenberg et al., 2010).

\subsubsection{Supervision Outcome (Trainee Counsellors' Satisfaction)}

The satisfaction of trainees is significant for them to uphold more effort and hard work in achieving goal and supervision. It influences their feedbacks and commitments and this cause certain impact on the effectiveness of supervision (Heppner \& Handley, 1981). The assisting relationship presented by supervisors is considered as sensitive to the needs of the counsellors during clinical training. Counsellor trainees who satisfied with their supervision indicated not only higher overall satisfaction but also create a stronger supervisory emotional bond according to Ladany, Ellis and Friedlander (1999).

Ramos-Sanchez et.al (2002) conducted a study on exploring the influence of negative interactions of supervisory relationship had on student's satisfaction with supervision. Those students who reported negative supervision experience including unethical behaviours were likely more to report lower satisfaction level compare to those who did. It was also supported by other studies (Heppner \& Roehlke, 1984, Russell \& Salmi, 1995) by stating that positive experience supervision will increase supervisee satisfaction. Therefore, it can be seen that the satisfaction of supervisee (trainee counsellor) is influenced by the kind of experience or interaction they had received during supervision in the supervisory relationship.

Bernard and Goodyear (1992) stated that supervision satisfaction was not entirely associated with effectiveness and having the rating of trainee on the quality of the supervision of how it fulfils his or her expectation and need not of the alternative ways to measure supervision satisfaction. According to Spence, Wilson, Kavanagh, Strong and Worrall (2001), stated the supervision outcome related 
research were conducted through various measure, such as the subjective rating of the quality of both trainees and supervisors' satisfaction on supervision, knowledge development among trainees, upgrading the skills and attitudes. This is obviously showed some research indicated the supervisees' (trainees') satisfaction as the predictor of the supervision effectiveness.

In summary, there are numerous factors influence the trainees; satisfaction which had been investigates in several previous studies. Knowledge about ways to enhance the satisfaction of supervisees (trainee counsellors) may help the counselling supervisors improve the training experience. For example, the negative event in supervision was affected the training experience of supervisees (trainee counsellors) during the supervision process. Knowledge and information become significant to incline the satisfaction of supervisees (trainee counsellors) training experience.

\section{Methodology/Materials}

This study was done by using quantitative research design in nature with correlational design in order to identify the relationship between the independent variables (supervisory style) and dependent variable (supervision outcome). Researcher was analyzed data using inferential and demographic analysis. The inferential analysis consisted Pearson's product-moment correlation coefficient and multiple regressions, then the demographic analysis is consisted mean, frequency, percentage and standard deviation.

\subsection{Population \& Sample}

Population were taken from Universiti Malaysia Sabah (UMS) and Universiti Utara Malaysia (UUM). The total trainee counsellor population from these two universities was 205 which 73 from UMS and 132 from UUM. Then, sample is choosing from the proportionate stratification method used in this research to determine the sampling fractions that corresponding to different strata. The sample size of each stratum is decided based on the number of counsellor trainees in the population from each university by using stratified random sampling. Stratified random sampling is used to determine the required sample size from the target population in this study because the sampling technique is suitable for the population that consists of number of subgroups and status and also for the research that required small simple size only. Randomly stratification sampling gives equal chance to everyone in the population to selected as sample (Ary, Jacobs \& Sorensen, 2009). In a proportionate stratified method, the sample size of each stratum is proportionate to the population size of the stratum (Hayes, 2020).

The formula is shown to determine sample size for different strata.

Table 1 Sample size for different strata

\begin{tabular}{ccc}
\hline Name of Universiti & $\begin{array}{c}\text { Sampling Proportion } \\
\text { N1/N }\end{array}$ & $\begin{array}{c}\text { Sample Size, } \mathbf{n} \\
* \mathbf{N} 1 / \mathbf{N}\end{array}$ \\
\hline UMS & $73 / 205$ & $100 * 73 / 205=35.6$ \\
UUM & $132 / 205$ & $100 * 132 / 205=64.4$ \\
\hline Total & $\mathbf{2 0 5 / 2 0 5}$ & $\mathbf{1 0 0}$ \\
\hline
\end{tabular}

\subsection{Instrumentation}

\subsubsection{Supervisory Styles Inventory (Friedlander \& Ward, 1984)}

There are two forms of Supervisory Styles Inventory (SSI) which are SSI-S and SSI-T. SSI-S is to be use by supervisors while SSI-T is used for the trainees (Friedlander \& Ward, 1984). In this research, SSI-T is being used since the perceptions of trainee counsellors are only being taken into consideration. It is a self-report questionnaire with total 33 items to measure three subscale which are attractive style that represent 7 items, interpersonally sensitive that represent by 8 items and task-oriented that represent by 10 items. There are 8 filter items causing no effect on the sum of scores and there is no clearly stating rationale for involving those 8 additional items by Friedlander \& Ward, 1984. The 7 points of Likert scale is used to rate the supervisory styles, ranging from 1 (Not 
Very) to 7 (Vey). For instance, if any participants rate 7 for the item 'supportive', that means the participants perceived that particular supervisors are closest to the supportive characteristics.

The final scoring for each subscale is calculated by add up the scores for all represented items then divide by the number of items. A mean score of the analysis is ranged from 1 to 7 while the higher score is definitely showed the obtained higher score of sub-variables become dominant style used. Friedlander \& Ward (1984) had estimated the high reliability of SSI by using internal consistency estimate of SSI ranged from $\alpha=0.76$ to $\alpha=0.93$ while the item-scale correlation for three subscales were as follows: attractive ranged from $\alpha=0.70$ to $\alpha=0.88$, interpersonally sensitive ranged from $\alpha=0.51$ to $\alpha=0.82$ and task-oriented ranged from $\alpha=0.38$ to $\alpha=0.76$. Additionally, test-retest reliability for attractive was $r=0.94$, interpersonally sensitive scale, $r=0.91$, task-oriented scale, $r=0.78$ and SSI total, $r=0.92$ (Friedlander \& Ward, 1984). The construct validity of SSI scales was identified by correlating with the scale items which measures the supervisory role behaviour. The result showed convergent validity representing high correlation between variables of the study (Friedlander \& Ward, 1984).

\subsubsection{Supervision Satisfaction Questionnaire (Ladany, Hill \& Nutt, 1996)}

In Supervision Satisfaction Questionnaire (SSQ), there are eight items with 4 point Likert scale; range between one (1) to four (4). For example, the first item is 'How would you rate the quality of the supervision you received?', whereby the 4-points Likert scale represents as 1 (Poor), 2 (Fair), 3 (Good) and 4 (Excellent). The final score would be in the range from a low of 8 to high of 32, whereby higher scores representing greater satisfaction in the supervision. Getting the score in the range of 8 to 20 as low satisfaction, 21 to 26 as medium satisfaction while 27-32 as high satisfaction (Ladany, Hill \& Nutt, 1996). The result shows only the trainees' satisfaction towards since the questionnaire is filled by trainees without considering supervisors' perceptions. The internal consistency estimate ranged from $\alpha=0.84$ to $\alpha=0.93$, indicating high reliability of the instrument (Ladany, Hill \& Nutt, 1996).

\subsubsection{Validity}

Table 2 Content Validation by Experts

\begin{tabular}{lc}
\hline \multicolumn{1}{c}{ Variables } & Content Validation Value \\
\hline Supervisory Styles & $1.0(100 \%)$ \\
Attractive & $.98(98 \%)$ \\
Interpersonally sensitive & $.93(93 \%)$ \\
Task-oriented & \\
Supervision Outcome & $.80(80 \%)$ \\
Trainee Counsellor's satisfaction & \\
\hline
\end{tabular}

\subsubsection{Reliability}

Table 3 Reliability of Instruments

\begin{tabular}{lc}
\hline Variables & $\begin{array}{c}\text { Cronbach Alpha Value Study } \\
(\alpha)\end{array}$ \\
& \\
Supervisory Styles & .91 \\
Attractive & .87 \\
Interpersonally sensitive & .92 \\
Task-oriented & \\
Supervision Outcome & .96 \\
Trainee Counsellor's satisfaction & \\
\hline
\end{tabular}

Before conducting the Pearson Correlation Product Moment and Multiple Regression analysis researcher is conducting the normality test. The test showed the Histogram, Normal P-P Plot of Regression Standardised Residual and Scatterplot were present to check the normality and 
homoscedasticity. Based on the observation of the plots and histogram, the data were said to be normally distributed and the variance of the residual reached homoscedasticity.

\section{Results and Findings}

\subsection{Descriptive Analysis of Respondents' Demography}

The sample consist of 26 percent of males $(n=26)$ and 74.0 percent of females $(n=74)$. The major of gender among respondent were females (Tables 6 ).

For the races of the trainee counsellors, there were 87.0 percent of Malay $(n=87)$ followed by others which are Bumiputera with 9.0 percent $(n=9)$ and Chinese with 4.0 percent $(n=4)$. This showed that Malay was the majority races that take part in this research and the least frequency was Chinese (Tables 6).

Other than that, for the year of study showed that trainee counsellors in Year 3 is more than trainee counsellors in Year 4 were Year 3 had 63.0 percent $(n=63)$ and Year 4 had 37.0 percent $(n=37)$ as showed in (Tables 6).

According to the 100 respondents, 36.0 percent of trainee counsellors $(n=36)$ came from Universiti Malaysia Sabah (UMS) while 64.0 percent of trainee counsellor $(n=64)$ came from Universiti Utara Malaysia (UUM). Overall, UUM respondents formed the majority (Tables 6 ).

Next, for the gender of the supervisors that the respondents rated, most of them were females with 79.0 percent $(n=79)$ and 21.0 percent $(n=21)$ were male supervisors while for the race of the supervisors, Malay also were the majority with 96.0 percent $(n=96)$ and followed by Chinese 4.0 percent $(n=4)$ as showed in (Tables 6$)$.

For the way to get current supervisors, most of the respondents answered that was based on their supervisor's choices with 41.0 percent $(n=41)$ followed by trainee counsellor's choices with 27.0 percent $(n=27)$ and others like agreement between trainee counsellors with faculty and arrangement by faculty or department with 27.0 percent $(n=27)$. The trainee counsellor's choice and others had the same number of respondents while he least ways respondents by the trainee counsellors was by getting emails with 5.0 percent $(n=5)$ as showed in (Tables 6$)$.

For the type supervision that the trainee counsellor showed that they got both type which were individual and group with 67.0 percent $(n=67)$ followed by individual only with 27.0 percent $(n=27)$. The least type of supervision was group with 6.0 percent $(n=6)$ as showed in (Tables 6).

Lastly, for the CGPA, most of the trainee counsellors got 3.00-3.49 with 50.0 percent $(n=50)$ followed by 3.50-4.00 with 41.0 percent $(n=41)$ and the least CGPA was 2.50-2.99 with 9.0 percent $(n=9)$ as showed in (Tables 6$)$. The mean for the CGPA was $M=3.89$ and the standard deviation was $\mathrm{SD}=0.86$. It showed based on the (Tables 7).

Table 4 Descriptive Information on Mean and Standard Deviations for Independent Variables

\begin{tabular}{lccc}
\hline \multicolumn{1}{c}{ Information } & $\mathbf{n}$ & Mean (M) & Std. Deviation (SD) \\
\hline Supervisory Styles & & & \\
$\quad$ Attractive & 100 & 40.89 & 6.26 \\
$\begin{array}{l}\text { Interpersonally } \\
\text { sensitive }\end{array}$ & 100 & 45.22 & 6.81 \\
Task-oriented & 100 & 44.70 & 6.86 \\
\hline
\end{tabular}

\subsection{Inferential Analysis}

$H_{0} 1$ : There is no significant relationships between supervisory style and the supervision outcome (trainee counsellors' satisfaction)

The statistical result showed, the supervisory styles were significantly related to the supervision outcome which was trainee counsellor's satisfactions with the coefficient $r=0.49$, at $p<0.05$ (Table 9). The null hypothesis was rejected because the $p$ value was less than .05 which was 0.00 . This means that there was significant relationship supervisory style and the supervision outcome (trainee counsellors' satisfaction). 
Table 5 Pearson's Product-Moment Correlation between supervisory style and the supervision outcome (trainee counsellors' satisfaction)

\begin{tabular}{lcc}
\hline \multicolumn{1}{c}{ Scales } & $r$ & Sig \\
\hline Supervisory Styles & 0.49 & 0.00 \\
Supervision Outcome & 1.00 & 0.00 \\
\hline
\end{tabular}

$\mathrm{H}_{02}$ : There is no significant relationship between supervisory style (attractive) and the supervision outcome (trainee counsellors' satisfaction)

Based on the result, the result revealed the supervisory style (attractive) and the supervision outcome (trainee counsellors' satisfaction) with the coefficient $r=0.48, p>0.05$ (Table 10). Therefore, the null hypothesis was rejected and this implied that there was significant relationship between supervisory style (attractive) and the supervision outcome (trainee counsellors' satisfaction).

Table 6 Pearson's Product-Moment Correlation between supervisory style (attractive) and the supervision outcome (trainee counsellors' satisfaction)

\begin{tabular}{lcc}
\hline \multicolumn{1}{c}{ Scales } & $\mathbf{r}$ & Sig \\
\hline Supervisory Styles (attractive) & 0.48 & 0.00 \\
Supervision Outcome & 1.00 & 0.00
\end{tabular}

$\mathrm{H}_{03}$ : There is no significant relationship between supervisory style (interpersonally sensitive) and the supervision outcome (trainee counsellors' satisfaction)

Based on the analysis, it showed that the relationship between supervisory style (interpersonally sensitive) and the supervision outcome (trainee counsellors' satisfaction) with the coefficient $r=0.48$, $p<0.05$ (Table 11). Due to smaller $p$ value, the null hypothesis was rejected. As conclusion, it implied that the supervisory style (interpersonally sensitive) significantly related to supervision outcome (trainee counsellors' satisfaction).

Table 7 Pearson's Product-Moment Correlation between supervisory style (interpersonally sensitive) and the supervision outcome (trainee counsellors' satisfaction)

\begin{tabular}{lcc}
\multicolumn{3}{c}{ supervision outcome (trainee counsellors' satisfaction) } \\
\hline \multicolumn{1}{c}{ Scales } & $\mathbf{r}$ & Sig. \\
\hline $\begin{array}{l}\text { Supervisory Styles } \\
\text { (interpersonally sensitive) }\end{array}$ & 0.48 & 0.00 \\
Supervision Outcome & 1.00 & 0.00 \\
\hline
\end{tabular}

$H_{04}$ : There are no significant relationship between supervisory style (task-oriented) and the supervision outcome trainee counsellors' (trainee counsellors' satisfaction)

Based on the findings it showed that supervisory style (task-oriented) was significantly related to the supervision outcome trainee counsellors' (trainee counsellors' satisfaction) with the coefficient $r=0.42, p<0.05$ (Table 12). Due to the smaller value of $p$ which was 0.00 , the null hypothesis was rejected. This showed supervisory style (task-oriented) significantly related to the supervision outcome trainee counsellors' (trainee counsellors' satisfaction).

Table 8 Pearson's Product-Moment Correlation between supervisory style (task-oriented) and the supervision outcome (trainee counsellors' satisfaction)

\begin{tabular}{lcc}
\multicolumn{1}{c}{ Scales } & $r$ & Sig. \\
\hline $\begin{array}{l}\text { Supervisory Styles } \\
\text { (task-oriented) }\end{array}$ & 0.42 & 0.00 \\
\begin{tabular}{l} 
Supervision Outcome \\
\hline
\end{tabular} & 1.00 & 0.00 \\
\hline
\end{tabular}


As conclusion for objective 1 , four of the hypotheses were all rejected that showed there was significant relationship between supervisory styles, supervisory style (attractive), supervisory style (interpersonally sensitive) and supervisory style (task-oriented) on the supervision outcome (trainee counsellors' satisfaction).

Research Objective 2:

To investigate the influence of supervisory style (attractive, interpersonally sensitive and taskoriented) on the supervision outcome (trainee counsellors' satisfaction).

This second objective is investigating the influence between the supervisory styles and the supervision outcome which was the trainee counsellor's satisfactions.

$H_{05}$ : There is no significant influence of supervisory style and the supervision outcome (trainee counsellors' satisfaction)

Multiple regression stepwise was conducted in or to predict the supervision outcome which was supervisees' (trainee counsellors') satisfactions. The prediction model contained only one predictor. There was significantly influence at $F(1,98)=30.39, p<.05$ and the variance is approximately 22.9 percent of the supervision outcome $\left(R^{2}=0.24\right.$, Adjusted $\left.R^{2}=0.23\right)$. From the result, it showed the supervision outcome was predicted by the supervisory styles. The raw and standardized regression coefficients of the predictor together with the correlations with supervision outcome, squared semi partial correlations and the structure coefficients were shown in Table 9. The variance score of supervisory style accounted approximately 23 percent. The linear regression equation for predicting supervision outcome $=0.08$ supervision outcomes +10.54 . Therefore, the result definitely failed to reject the null hypothesis. In summary, the supervisory styles influenced the supervision outcome which was the trainee counsellor's satisfaction (Table 9).

Table 9 Influence of supervisory style and the supervision outcome (trainee counsellors' satisfaction)

\begin{tabular}{llllll}
\hline Predictor & $\mathrm{B}$ & $\mathrm{SE}-\mathrm{b}$ & Beta & Pearson $\mathrm{r}$ & $\mathrm{sr}^{2}$ \\
\hline $\begin{array}{l}\text { Supervision } \\
\begin{array}{l}\text { Outcome (Constant) } \\
\text { Supervisory Styles }\end{array}\end{array}$ & 0.08 & 2.78 & 0.00 & 0.00 & 0.00 \\
& 0.02 & 0.49 & 0.49 & 0.23 \\
\hline
\end{tabular}

$H_{06}$ : There is no significant influence between supervisory style (attractive, interpersonally sensitive and task-oriented) and the supervision outcome (trainee counsellors' satisfaction)

The subscales of supervisory style are attractive style, interpersonally sensitive and task-oriented style were calculated by using a stepwise Multiple Regression analysis to predict the supervision outcome which was trainee counsellor's satisfactions based on the supervisory styles of attractive. The prediction model contained four predictors with no variables removed. Among the four variables, all of them showed significant correlated but stronger in attractive and interpersonally sensitive. For attractive, the correlations were statistically significant $F(1,98)=29.89, p<.05$ and the variance showed 22.6 percent of the supervision outcome $\left(R^{2}=0.23\right.$, Adjusted $\left.R^{2}=0.23\right)$. For interpersonally sensitive, the correlations were statistically significant $F(1,98)=29.05, p<.05$ and the variance of the supervision outcome at 22.1 percent of the variance $\left(R^{2}=0.23\right.$, Adjusted $\left.R^{2}=0.22\right)$ and for task-oriented, the relationship was statistically significant $F(1,98)=23.06, p<.05$ and the variance of supervision outcome accounted approximately 18.2 percent $\left(R^{2}=0.19\right.$, Adjusted $\left.R^{2}=0.18\right)$. The outcome of supervision was primarily influenced by the supervisory styles. The raw and standardized regression coefficients of the predictor together with the correlations with supervision outcome, their value of squared semi partial correlations and the structure coefficients were shown in the table. Linear regression equation that predicted the supervision outcome $=0.51$ supervision outcomes +10.88 . Therefore, from this result the null hypothesis was failed to reject. 
Table 10 Influence of supervisory styles (attractive, interpersonally sensitive and task-oriented) and the supervision outcome (trainee counsellors' satisfaction)

\begin{tabular}{|c|c|c|c|c|c|}
\hline Predictor & $b$ & SE-b & Beta & Pearson $r$ & $s r^{2}$ \\
\hline $\begin{array}{l}\text { Supervision } \\
\text { Outcome } \\
\text { (Constant) }\end{array}$ & 10.88 & 2.73 & 0.00 & 0.00 & 0.00 \\
\hline $\begin{array}{l}\text { Supervisory } \\
\text { Styles of } \\
\text { Attractive }\end{array}$ & 0.28 & 0.17 & 0.29 & 0.48 & 0.23 \\
\hline $\begin{array}{l}\text { Supervisory } \\
\text { Styles of } \\
\text { Interpersonally } \\
\text { Sensitive }\end{array}$ & 0.19 & 0.16 & 0.29 & 0.48 & 0.22 \\
\hline $\begin{array}{l}\text { Supervisory } \\
\text { Styles of Task- } \\
\text { Oriented }\end{array}$ & 0.04 & 0.11 & 0.07 & 0.44 & 0.18 \\
\hline
\end{tabular}

\section{Discussion}

Result from this research showed, the first hypothesis is rejected and that implied there is significant relationship between supervisory style and the supervision outcome (trainee counsellors' satisfaction). This finding was consistent with the previous studies of (Fernando \&Hulse-Killacky, 2005; Berger, 2012; Josephine, 2018) where their research showed that there was significant positive relationship between supervisory styles and supervision outcome with the supervision outcome scores increase as the supervisory styles scores also increases. This result also supported by Bussey (2015), where in her research the result concluded that the variables of supervisory style and working alliance do relate significantly to satisfaction with supervision.

Second hypothesis also rejected by the result. Finding showed there is a significant relationship between supervisory style (attractive) and the supervision outcome (trainee counsellors' satisfaction). This finding was consistent with the previous research of Fernando and Hulse-Killacky (2005) which showed that the attractive styles had significant relationship with the satisfaction $(r=0.67)$. The past research of Josephine (2018) also showed that the consistent result of the significant relationship with $(r=0.58)$ but in this current study, the strength of relationship was lower which was $r=0.48$.

In addition, the third hypothesis and fourth hypotheses are also rejected. This is clearly showed the findings have significant relationship between supervisory style (interpersonally sensitive and task-oriented) and supervision outcome (trainee counsellors' satisfaction). This result is contradicted with previous research by Josephine, et.al (2018), it also showed that there is no significant relationship between supervisory style (interpersonally sensitive) and the supervision outcome (trainee counsellors' satisfaction) with the coefficient correlated $r=0.63$ which more higher result that the current study with $r=0.48$. The study showed that the interpersonally sensitive styles was the higher results followed by task-oriented styles with $r=0.60$ and attractive style was the lowest with $r=0.58$. Besides that, the Berger (2012) also showed there is no significant relationship between task-oriented styles and the supervision outcome. The reason is probably due to the participants recruited for the previous studies were those who were more experienced and advanced in the counselling field compared to the current study.

Thus, for hypotheses five and six showed there is a significant influence on supervisory style (attractive, interpersonally sensitive and task-oriented) and the supervision outcome (trainee counsellors' satisfaction). It is also showed that there is direct connection between the supervisee's perception of the trainee counsellors' supervisors' style and the perception of supervision outcome and perhaps the process of the supervision. The finding was supported by the previous research of 
(Berger, 2012; Fernando \&Hulse-Killacky, 2005; Shuss, 2012) whereby the results of the current study showing the interpersonally sensitive style was significantly predicted the supervision outcomes was consistent with the results of the previous studies. According to the research by Josephine (2018), the results showed that the three styles also give influence on the supervision outcome but interpersonally sensitive was the strongest influence followed by task-oriented and attractive styles. In the current research, it showed that the interpersonally sensitive and the attractive styles was found to be highly correlated to the positive supervising that the trainee counsellors experience where the supervisee always update and facilitate the trainee counsellors in their supervision of the session with their clients. Based on the previous study, it could be concluded that all the styles give influence on the supervision, but interpersonally sensitive and attractive styles give more beneficial learning environment for the supervisors to help the trainee counsellor to be a professional counsellor in the future.

\section{Conclusion}

In summary, the supervisory styles had significant relationship and significant influence with the supervision outcome which was the trainee counsellor's satisfaction. Among the three supervisory styles, attractive and interpersonally styles contributed the most influence on the supervision outcome followed by task-oriented.

From this research it is clearly showed the different developmental level of supervisee could make difference in the findings of the relationship between supervisory styles and supervision outcome. So that, the supervisor should concern on the developmental level of supervisees in order to interact and communicate with them. For future studies, researcher suggested to investigate the cause and impact on the satisfaction to provide various information to the supervision field. In addition, in order to increase the accuracy of the data the distribution of questionnaires should do face to face.

\section{References}

1. Baker, D. E. (1991). The relationship of the supervisory working alliance to supervisor and supervisee narcissism, gender, and theoretical orientation. Dissertation Abstracts International, 51(7-B), 1484B. (University Microfilms No. 90-14), 392.

2. Bernard, J. M., \& Goodyear, R. K. (2009). Fundamentals of clinical supervision (3rd ed.). Boston: Pearson.

3. Bernard, J. M., \& Goodyear, R.K. (1992). Fundamentals of clinical supervision. Boston, MA: Allyn and Bacon.

4. Bussey, L; , E. (2015). The supervisory relationship: How style and working alliance relate to satisfaction among cyber and face to face supervisees. Doctoral Dissertations, University of Tennessee, Retrieve from http://trace.tennessess.edu/utk_graddiss/3564

5. Corey, G., Haynes, R., Moulton, P., \& Muratori, M. (2010). Clinical supervision in the helping professions: A practical guide. (2nd Ed.) Alexandria, VA: American Counseling Association.

6. Dye, H.A. \& Borders, L.D. (1990). Counseling supervisors: Standards for preparation and practice. Journal of Counseling and Development, 69, 27-32.

7. Fernando, D. M., \& Hulse-Killacky, D. (2005). The Relationship of supervisory styles to satisfaction with supervision and the perceived self-efficacy of master's-level counseling students. Counselor Education and Supervision, 44(4), 293-304.

8. Friedlander, M. L., \& Ward, L. G. (1984). Development and validation of the Supervisory Styles Inventory. Journal of Counseling Psychology, 31, 541-557.

9. Hayes, A., (2020). Stratified random sampling. Retrieved from https://www.investopedia.com/terms/stratified_random_sampling.asp

10. Hensley, L. G., Smith, S. L., \& Thompson, R. W. (2003). Assessing competencies of counselors intraining: Complexities in evaluating personal and professional development. Counselor Education and Supervision, 42(3), 219-230. 
11.Herbert, J. T., \& Ward, T. J. (1990). Supervisory Styles among rehabilitation counseling practical supervisors. Rehabilitation Education, 4, 203-212.

12.Ladany, N., \& Lehrman-Waterman, D.E. (1999). The content and frequency of supervisor selfdisclosures and their relationship to supervisor style and the supervisory working alliance. Counselor Education and Supervision, 38, 143-160.

13.Ladany, N., Hill, C. E., \& Nutt, E. A. (1996). Supervisory Satisfaction Questionnaire.

14.Ladany, N., Lehrman-Waterman, D. (1999). The content and frequency of supervisor selfdisclosures and their relationship to supervisor style and the supervisor working alliance. Counselor Education and Supervision, 38, 143-160.

15.Ladany, N., Walker, J. A., \& Melincoff, D. S. (2001). Supervisory Style: Its relation to the supervisory working alliance and supervisor self-disclosure. Counselor Education and Supervision, 40(4), 263-275.

16.Ladany, N., Walker, J. A., \& Melincoff, D. S. (2001). Supervisory style: its relation to the superisory working alliance and supervisor self-disclosure. Counselor Education and Supervision, 40(4), 263275.

17.Morgan, M. M., \& Sprenkle, D. H. (2007). Toward a common-factors approach to supervision. Journal of Marital and Family Therapy, 33(1), 1-17.

18.Nelson, M. L., \& Holloway, E. L. (1990). Relation of gender to power and involvement in supervision. Journal of Counseling Psychology, 37(4), 473-481.

19.Nelson, M., \& Friedlander, M. L. (2001). A close look at conflictual supervisory relationships: The trainees's perspective. Journal of Counseling Psychology, 48, 384-395. http://dx.doi.org/10.1037/0022-0167.48.4.384.

20.Nor Mazlina Ghazali, Josephine Lo Jing Wen, Azzahrah Anuar \& Edris Aden. (2018). Reliability Analysis of Supervisory Styles Inventory: A Preliminary Study. Journal of Cognitive Sciences and Human Development. Vol. 3(2).

21.Nur Hafizah Mohd Ali, Siti Aishah Hassan and Othman Jailani (2014). The supervisory styles of supervisors as perceived by counselling interns in Malaysia. Asian Journal of Applied Sciences. Vol (2)2321-0893. Retrieve from www.ajouronline.com

22.Patton, M. J., \& Kivlighan, D. M., Jr. (1997). Relevance of the supervisory alliance to the counseling alliance and to treatment adherence in counselor training. Journal of Counseling Psychology, 44(1), 108-115.http://dx.doi.org/10.1037/0022-0167.44.1.108.

23.Ramos-Sanchez, I., Esnil, E., Riggs, S., Wright, L, L., Goodwin, A., Osachy Touster, L., Ratanasiripong, P., \& Radolfa, E. (2002). Negative supervisory events; effects on supervision satisafaction and supervisory alliance. Professional Psychology: Research and Practice, 33(2), 197202.

24.Spence, S. H., Wilson, J., Kavanagh, D., Strong, J., \& Worrall, L. (2001). Clinical supervision in four mental health professions: A review of the evidence. Behavior Change, 18, 135-155.

25.Terranova-Nneberg, J. (2013). A quantitative investigating supervisory styles, satisfaction with supervision and self-efficacy among female clinical training supervisees. Retrieved from https://search.proquest.com/docview/1459239531?pq-origsite=gdcholar. 